\title{
Building a national pro-choice alliance in Mexico: Evaluation of the Alliance media campaign to promote access to safe, free, and legal abortion services
}

Population Council

Follow this and additional works at: https://knowledgecommons.popcouncil.org/departments_sbsr-rh

Part of the Demography, Population, and Ecology Commons, Family, Life Course, and Society Commons, International Public Health Commons, and the Women's Health Commons How does access to this work benefit you? Let us know!

\section{Recommended Citation}

"Building a national pro-choice alliance in Mexico: Evaluation of the Alliance media campaign to promote access to safe, free, and legal abortion services," fact sheet. Washington, DC: Population Council, 2016. 


\section{BACKGROUND}

Since decriminalization more than eight years ago in 2007 , more than $152,500^{1}$ women have accessed elective legal abortion in Mexico City. The Mexico City Ministry of Health (MX-MOH) facilities offer free services to women residing in the city with proof of residency ${ }^{2}$. These health facilities provide quality and confidential abortion services by adhering to strict international and evidencebased safety protocols, implemented by trained and skilled providers using state of the art technology. Nevertheless, up until last year, the MX-MOH health services had not been advertised as efficiently as those of the private abortion clinics, despite having enhanced benefits, such as offering free services and thereby avoiding an out-of-pocket expense for women ${ }^{3}$.

\section{APPROACH}

The Population Council (PC) and Alliance partners (Grupo Información Reproducción Elegida, Catholics for the Right to Decide, Ipas Mexico and Equidad de Género), with support from an Anonymous Donor, designed a legal abortion media campaign aimed at informing women in Mexico City of their legal right to a safe, free elective abortion during the first twelve weeks of pregnancy. The impetus for the campaign was the apparent lack of knowledge regarding the legality of abortion in Mexico City among low income, marginalized women of reproductive age combined with the inadequate number of $\mathrm{MX}-\mathrm{MOH}$ facilities equipped to provide services to women living in an expansive metropolitan area such as Mexico City. The Council and the Alliance focused the core campaign message on informing women that abortion is safe, free, and legal at MX-MOH facilities. The creative concept of "safe spaces 4 " was tested and when proven successful, it was commissioned to a local marketing firm. PC tested and validated the campaign messages through focus groups as well as street intercept surveys with marginalized women to ensure appropriate message comprehension and cultural relevance.

The campaign, which took place during the fall of 2014 and winter of 2015, included two main components: mass media messaging in Mexico City and interpersonal

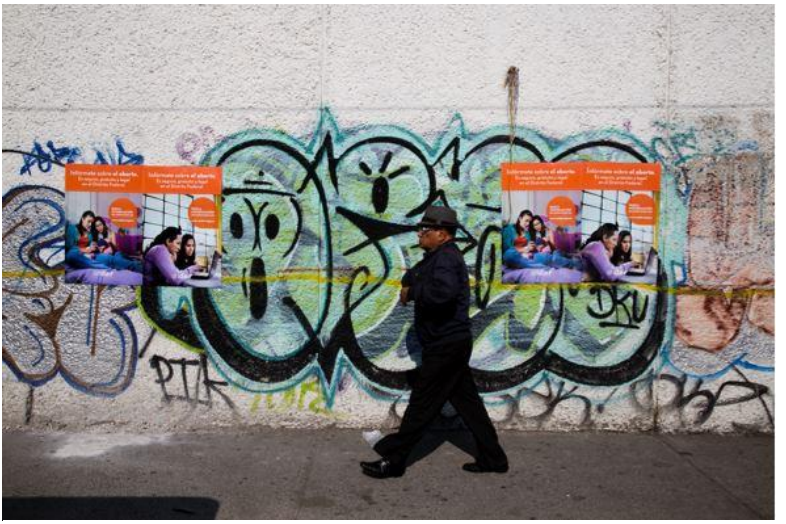

Pro-choice campaign posters hang on a wall in Iztapalapa. (Photo by Claudia Guadarrama)

community outreach, specifically in the Iztapalapa district which was chosen due to its high concentration of women of reproductive age, high poverty rates, low average educational attainment, and high adolescent fertility rates. The Alliance website (www.andar.org. $m x$ ) serves as the information nucleus for the campaign. The website is the safe space where women can find adequate and objective information on legal abortion. It reinforces the message of access to the safe, free, and legal abortion services offered by the MX-MOH clinics and hospitals through clear, step-by-step information for women needing abortion services as well as a Frequently Asked Questions (FAQ) section. The website also includes contact options such as an e-mail that is answered daily by campaign promoters, a link to the Alliance Facebook page which enables real time interaction online, and a printable take-away document containing all the information found on the website 5 . The campaign is also featured in the Women on Web webpage under the Population Council Mexico office.

The mass media component of the campaign included adhoc radio spots aired on commercial radio, campaign posters inside Metrobus (public transport) stations, and videos on screens inside Metrobus units. Wrap advertising 6 on public transit buses that ran through two busy routes, one of them within Iztapalapa, was used to further strengthen the presence of the campaign. For the community outreach component, youth advocates from Ddeser (Equidad's youth network) carried out the dissemination of pro-choice campaign messages on phone
The Population Council conducts research and delivers solutions that improve lives around the world. Big ideas supported by evidence: It's our model for global change. popcouncil.org
POPULATION COUNCIL

Ideas. Evidence. Impact. 
booths, walls, sidewalks, streetlights and schools in Iztapalapa. Other activities included public talks and hosting information fairs at community centers, high schools and one public university in Iztapalapa. A final component of the media campaign was based on face-to-face information sharing activities. These included more than 20 events in which advocates would speak with women, dispel myths around abortion, and disseminate informational resources and merchandise. A series of street performances by a group of well-known feminist cabaret actresses called "Las Reinas Chulas" (The Fair Queens) were also quite popular.

\section{IMPACT}

Since the campaign launch in March 2015, the Alliance website has received a constant flow of visitors with more than 110,000 page visits as of January 2016 . Furthermore, Google website analytics show that over $45 \%$ of users access the website directly which indicates that site visitors know the specific address (as found on all campaign products) rather than stumbling upon it when using a search engine. The campaign e-mail address received over 300 messages as of January 2016 and the Facebook direct messaging service received an additional 300 real-time questions from women (or their partners) seeking information about legal abortion services and access to low-cost contraception.

In order to evaluate the effect among women potentially exposed to the campaign, three successive street-intercept surveys with random samples of 550 women of reproductive age (18-49) per survey were completed. ${ }^{7}$ Respondents were selected from public transit hubs (Metrobus stations) in the intervention area at baseline (March 2015), midterm (August 2015), and endpoint (October 2015). The survey questionnaire was designed to measure respondents' exposure to campaign components, retention of campaign messages and awareness of the fact that abortion is safe, free, and legal at MX-MOH facilities. Major findings include:

- Knowledge regarding the legality of elective abortion in Mexico City is almost universal. Nevertheless, there is still a lack of knowledge among women on how to access abortion services (55\% at baseline versus $66 \%$ at endline) and that abortion is free of charge at MX-MOH clinics and hospitals (51\% at baseline versus 54\% at endpoint).

- Alliance campaign message recall increased by $10 \%$ between August and October 2015, indicating that the campaign slogan was memorable.

- When asked to spontaneously recall the type of campaign product either seen or heard, respondents mentioned posters (32\%), advertising on bus ${ }^{7}(29 \%)$, graffiti (25\%), pull-tab posters (16\%), Facebook page (15\%), and flyers (12\%).

- Interviewer-assisted recall of posters placed inside Metrobus stations and in different areas of Iztapalapa (distributed by youth advocates) was recalled by $33 \%$ of women in August and 32\% in October, followed by the wrap advertising on buses (28\% and 29\% in August and October, respectively).

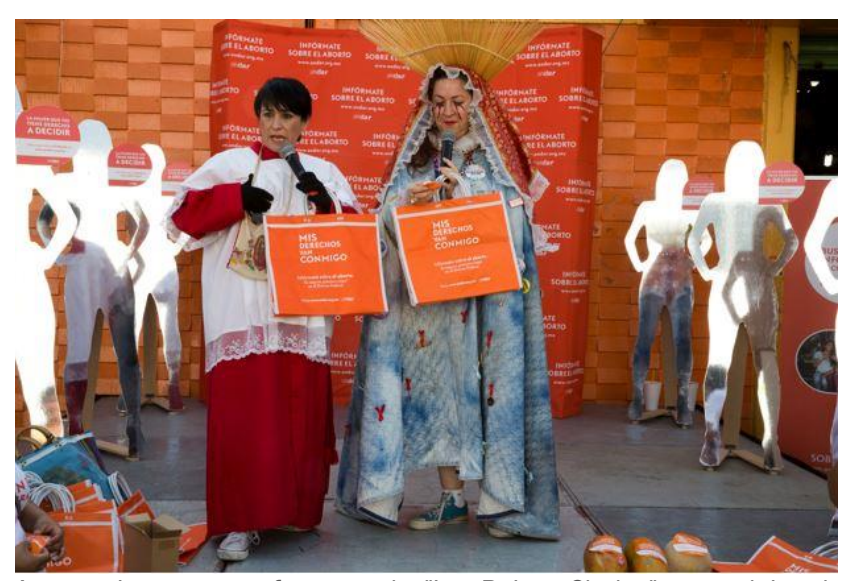

A campaign street performance by "Las Reinas Chulas", an acclaimed Mexican cabaret group. (Photo by Claudia Guadarrama)

- Both for spontaneous and interviewer-assisted recall, campaign product recall was the same (albeit in a different order). This suggests that women spontaneously recognized the campaign products without visual aids or cues.

The evaluation results show that despite the success of the media campaign, knowledge and access barriers still exist. A potential solution for future communication campaign interventions will include a focus on behavior change strategies. Additionally, providing clearly defined actions and steps to access services rather than solely providing information about the Mexico City elective abortion law may prove helpful.

\section{REFERENCES}

1. According to official data for MX-MOH hospitals and clinics (December, 2015)

2. At the MX-MOH clinics women from other states also receive services with a sliding fee scale.

3. As comparison, the cost of an abortion in private facilities ranges from $\$ 2,500$ - $\$ 10,000$ pesos ( $\$ 140-\$ 555$ USD), depending on the clinic, location and type of method selected (medical or surgical).

4. A "safe space" generally involves an adolescent girl-only space, where adolescent girls are free to interact and participate with their peers. The Council has developed a number of "safe spaces" programs that address the needs of vulnerable adolescents, particularly girls. Please see: http://www.popcouncil.org/uploads/pdfs/TABriefs/39_SafeSp aces.pdf

5. The idea behind being able to have a printable PDF document was that women with no access to Internet at home, or those wishing more privacy, could carry the information with them.

6. Wrap advertising refers to the wrapping of a public transport vehicle in advertisement (either using paint or vinyl sheets).

7. Because of our limited sample, the size of the observed changes falls within the margin of error, (i.e. results are not statistically significant). However, they do show positive trends.

8. They did not clarify what type of advertising (wrap, TV-screen or poster) 